\title{
Factors Associated with the Length of First Time Hospitalization in a Referral Psychiatric Hospital in North of Iran
}

\author{
Abolfazl Hossein Nattaj, ${ }^{1}$ Mehran Zarghami, ${ }^{2,3}$ Jamshid Yazdani-Charati, ${ }^{1,4,}{ }^{*}$ Mohammad Vahedi, ${ }^{5}$ \\ Ameneh Sheikholeslami, ${ }^{1}$ and Zahra Faghani ${ }^{1}$ \\ ${ }^{1}$ Department of Epidemiology and Biostatistics, School of Health, Mazandaran University of Medical Sciences, Sari, IR Iran \\ ${ }^{2}$ Psychiatry and Behavioral Sciences Research Center, Addiction Institute, Mazandaran University of Medical Sciences, Sari, IR Iran \\ ${ }^{3}$ Department of Psychiatry, School of Medicine, Mazandaran University of Medical Sciences, Sari, IR Iran \\ ${ }^{4}$ Health Sciences Research Center, Mazandaran University of Medical Sciences, Sari, IR Iran \\ ${ }^{5}$ Department of Microbiology, School of Medicine, Mazandaran University of Medical Sciences, Sari, IR Iran \\ "Corresponding author: Jamshid Yazdani-Charati, Department of Epidemiology and Biostatistics, School of Health, Mazandaran University of Medical Sciences, Sari, IR Iran. \\ Tel: +98-1133543081-3, Fax: +98-1133542473, E-mail: jamshid.charati@gmail.com
}

Received 2016 June 26; Revised 2016 August 24; Accepted 2016 November 27.

\begin{abstract}
Background: Length of hospitalization is an important indicator for optimal management and to reduce and save the costs.

Objective: Considering the limited hospital capacity as a referral center for psychiatric patients, the high prevalence of the disease, and the high expense of the treatment, this study aimed to identify the factors associated with psychiatric patients' length of hospitalization.

Methods: The data were obtained from the records of all patients hospitalized for the first time since the April 2007 to the March 2012. The data collection tool was a checklist comprising of demographic variables, variables related to the socioeconomic status, psychiatric disorders, and the related variables such as length of hospitalization and a previous history.

Results: In the present study, 2397 (72.8\% males and 27.2\% females) medical documentations were investigated. Median length of stay was 25 days. Using the Cox model, the variables including age, educational level, material status, employment, the insurance status, the history of hospitalization at psychiatric center, type of treatment and disorder, duration of disorder, the referral source , and hospitalization during religious months (Ramadan and Muharram) and agricultural seasons had a significant relationship with the length of hospitalization (P value $<0.05$ ).

Conclusions: The patients with anxiety disorders and substance dependence and also patients with the comorbid anxiety disorders and substance dependence had a higher hospitalization length than patients with psychotic disorders. Substance dependence and variables such as insurance status had a significant relationship with the length of hospitalization. In patients with the comorbid substance dependence and anxiety disorders, women had a longer length of hospitalization.
\end{abstract}

Keywords: Cox Model, Length of Stay in Hospital, Psychotic Disorders

\section{Background}

Health care and treatment are basic requirements of each society. Since the health care and treatment investment lead to the manpower productivity and increase of production, therefore finance allocation and proper using of resources play an important role in this field (1).

Hospitals are the main and key centers in the health system with crucial roles in rendering health care services. For this importance, the hospitals have the effective role in the efficacy of health system (2). These health settings consume half of the national budget in the health sector (3).

Demand for hospital services is progressively increasing. Analysis of the related factors of hospital services is one of the ways that is used by the governments to manage the hospital services (4).

Analysis of the information related to the hospitals per- formance and rate of efficient services helps the management and decision making of the managers. Length of hospital stay is a main index which nowadays is used extensively and is one of the simplest aspects of hospital activity. This index is used for various objectives, including the hospital care managements, and quality of using hospital services for the hospital management (5).

Length of hospital stay is generally used as an efficiency index. In this regard, the reduced length of hospitalization can lead to the increase in efficiency of the number of patients or the reduced number of hospital beds (6).

The reduced unnecessary hospital stay can lead to the more health services to a higher number of patients, and reduce monetary pressure and establish the new health care setting (7).

For centuries, the psychiatric patients were treated 
brutally, since it was believed that Satan and metaphysic agents are the cause of mental disorders. Psychotic patients were treated with severe physical torture to force the Satan's leave the body of the patients, hence the patients were cleansed with hot water, they were beaten with slash, and they were deprived of eating and were tortured.

Lifetime prevalence of mental disorders has been observed in more than $25 \%$ of the population and the point prevalence was $10 \%$ of the adult population, worldwide. Accordingly, one in four persons is diagnosed with these disorders. About $13 \%$ of the diseases were recorded due to the mental disorders in 2006 that will be increased to $16 \%$ by 2020 (8).

In the ranking of burden of the diseases in Iran, psychiatric disorders had the second rank after road traffic accidents (DALY 3988 per 100,000 populations) (9).

In Iran, the prevalence of mental disorders is $20 \%$ in the population above 15 years old. Mood and anxiety disorders have the highest prevalence. Studies in the East Azerbaijan, Bushehr, and Chaharmahal and Bakhtiari provinces showed that mental disorders composed $14.5 \%$ of the total diseases. In addition, mental disorders were the main cause of disability in Iran. In the children and adults, the socio-psychological problems (except mental disorders) such as violence, crime and academic failure showed the prevalence of more than $20 \%$ (8).

The mental disorders have devastating effects by imposing direct expenses (the money expended for the diagnosis, treatment, rehabilitation and prevention) and indirect expenses (reducing of manpower, reduction of productive power of society, family expenses) since they lead to the most cases of disabilities in Iran (8).

In several studies, some cases were selected and followed until faced a problem. Therefore, one of the interesting points of the workers was the time between entering the study and the time of the occurrence of the intended event and determining the relation between the supporting variables to determine the risk factors. In the present study, the time of observation followed by the censor data termed as survival data and the statistical methods for the statistical analysis are termed as survival analysis (10-12).

\section{Objective}

Considering the limited capacity of the hospitals as the referring centers for psychiatric patients, the high prevalence of the disease, and the high expense of the treatment, this study aimed to identify the factors affecting the duration of hospitalization to help the administrators of hospitals to improve the efficacy of the treatment and reduce the expenses and waste of hospital resources.

\section{Materials and Methods}

The data were obtained from the medical documentations of the patients at Sari Zare hospital. This hospital is a referral university hospital in north of Iran (Sari- the capital of Mazandaran province which is an agricultural area), serving 3.074 million people. The study subjects comprised all psychiatric patients with the first time hospitalization from the April 2007 to the March 2012. The data collection tool was a checklist comprising of the length of hospitalization variables, gender, age, marital status, number of children, educational level, accommodation condition (native or expatriate), living area (urban or rural), profession, employment, the relation between educational level and occupation, the insurance status, a history of hospitalization at the psychiatric center, substance dependence, type of disorder, duration of disorder, physical health condition, suicidal idea, a history of suicide attempt, homicidal idea, the referral source, type of treatment, hospitalization during the religious months ( Ramadan and Muharram, in which exaggeration in religious praying and rituals take place in this region), and the agricultural seasons. We used a simple categorization for the type of disorder; i.e. anxiety disorders (including generalized anxiety disorder, acute stress disorder, posttraumatic stress disorder, obsessive-compulsive disorder, panic disorders, phobias, etc.), mood disorders (including depressive and bipolar disorders, etc.), psychotic disorders (including acute psychotic disorder, schizophreniform disorder, schizophrenia, schizoaffective disorder, delusional disorders, etc.) and substance dependence (including opioid, cannabinoid, amphetamine and other substance dependencies).

The patients with the improper information from admission to the discharge, or discharge before the beginning of treatment, also discharge against medical advice (AMA) were excluded from the study.

Data from rehospitalization during the study period were not considered. The Cox semi parametric regression model was used to determine the effects of the variables on the length of hospital stay. $\mathrm{T}$ is considered as the length of hospitalization due to the psychiatric disorders. Then, the value of $\mathrm{T}$ can be regarded as a probability distribution. The main form of this model consists of (Equation 1):

$\ln (h(T))=\ln \left(h_{0}(T)\right)+\sum_{i=1}^{p} x_{i} \beta_{i}$

Where $\mathrm{x}_{1}, \mathrm{x}_{2}, \ldots, \mathrm{x}_{\mathrm{p}}$ are covariates, $\beta_{1}, \beta_{2}, \ldots, \beta_{\mathrm{p}}$ are the estimated regression coefficients and $h_{0}(T)$ is the baseline hazard rate when all covariates are equal to zero $(13,14)$.

All of the obtained data were analyzed using the STATA 13 software and SPSS-20 and the value of $\alpha=0.05$ was considered significant. 


\section{Results}

In the present study, 2397 (72.8\% males and $27.2 \%$ females) medical documentations were investigated. Demographic information is shown in Table 1.

Table 1. Demographic Features of the Psychiatric Patients with the First Time Hospitalization at the Zare Psychiatric Hospital in Sari, Mazandaran, Iran, 2007 - 2013

\begin{tabular}{|c|c|c|}
\hline The Qualitative Variable & & No. (\%) \\
\hline \multirow{2}{*}{ Gender } & Male & $1745(72.8)$ \\
\hline & Female & $652(27.2)$ \\
\hline \multirow{4}{*}{ Age, $y$} & $0-14$ & $29(1.2)$ \\
\hline & $15-29$ & $906(37.8)$ \\
\hline & $30-44$ & $963(40.2)$ \\
\hline & $45-60$ & $442(18.4)$ \\
\hline \multirow{6}{*}{ Marital status } & $>60$ & $57(2.4)$ \\
\hline & Married & $1117(46.6)$ \\
\hline & Single & $929(38.8)$ \\
\hline & Divorced & $310(13)$ \\
\hline & died spouse & $33(1.4)$ \\
\hline & Rural & $992(41.4)$ \\
\hline \multirow[t]{4}{*}{ Living area } & Urban & $1387(58)$ \\
\hline & homeless & $15(0.6)$ \\
\hline & Illiterate & $223(9.3)$ \\
\hline & elementary & $421(17.6)$ \\
\hline \multirow[t]{3}{*}{ Educational level } & Guidance & 808 (33.7) \\
\hline & $\begin{array}{l}12 \text { standard and } \\
\text { post-secondary }\end{array}$ & $802(33.5)$ \\
\hline & high school & $126(5.3)$ \\
\hline
\end{tabular}

In this study, the Kaplan-Meier estimator of the survival function (hospitalization period) was 29.1 days (CI 95\%: 28.14 - 30.07) and the median of hospitalization period was equal to 25 days (CI 95\%: 24.05 - 25.95). The survival function curve for the patients with their first time hospitalization at the psychiatric ward of the Zare Psychiatric hospital of Sari from 2007 to 2013 is shown in Figure 1.

Considering the PH hypothesis, it was noticed that this hypothesis is present for all of the independent variables in the model.

To determine the effects of different levels of one qualitative variable on the hospitalization period we used the indicter variables (two in two) and in each of these qualitative variables we considered its level as the base level. In addition, in order to determine the effect of supporting variables on the survival time, initially, the single variable Cox regression model was used for all of the variables,

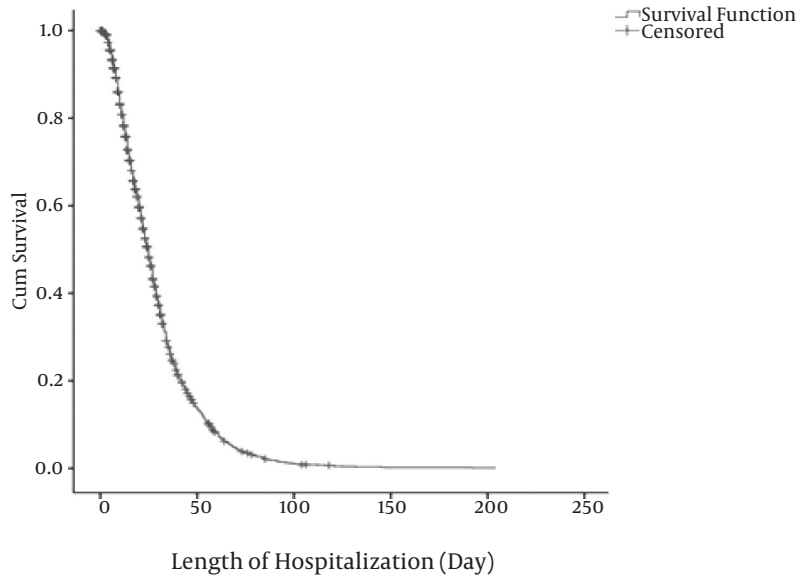

Figure 1. The Survival Function for the Patients with the First Time Hospitalization at Zare Psychiatric Hospital from 2007 to 2013

separately. Then, all of the variables in the mentioned model with $\mathrm{P}>0.3$ were excluded and those with $\mathrm{P}<0.3$ were entered as the risk models suitable for the Cox multivariables.

Table 2 shows the results obtained from the Cox multivariable regression model for the variables with significant effects on the length of hospitalization.

As seen in table 2, the socio demographic variables such as age, educational level, living area, religious months, and agricultural seasons had a significant relationship with the length of hospitalization (P value < 0.05).

In addition, according to the Table 2 , the clinical characteristics such as type of treatment, type of disorder (mood, anxiety, and substance dependency), and duration of the disorder had a significant relationship with the length of hospitalization (P value $<0.05)$.

\section{Discussion}

The total stay of psychiatric patients in the hospital is related to the hospital costs. Hospital cost constitutes one of the most important factors for managers. In the present study, the patients with insurance, a pervious hospitalization due to other diseases, hospital stay during the religious months and agricultural seasons and with a longer hospitalization period had a shorter time of hospitalization.

The patients aged 0 - 14 years compared with the 30 - 44 years and single and divorced cases compared to the married cases had a shorter hospitalization, respectively. Accordingly, these groups of the patients (30 - 44 years and 
Table 2. The Significant Variables in the Cox Multi-Variable for the Patients with the First Time Hospitalization at Zare Psychiatric Hospital from 2007 to 2013

\begin{tabular}{|c|c|c|c|c|c|c|}
\hline Variable & The Studied & The Base Level & Risk Ratio & P Value & & Distance confidence of $95 \%$ for the risk ratio \\
\hline Insurance & Has & Nil & 0.71 & 0.00 & 0.59 & 0.84 \\
\hline $\begin{array}{l}\text { A history of hos- } \\
\text { pitalization(for } \\
\text { other disease) }\end{array}$ & Has & Nil & 0.84 & 0.00 & 0.76 & 0.93 \\
\hline $\begin{array}{l}\text { Hospitalization } \\
\text { in religious } \\
\text { months }\end{array}$ & Has & Nil & 0.76 & 0.00 & 0.69 & 0.85 \\
\hline Age(year) & 0.14 & $30-40$ & 0.57 & 0.01 & 0.36 & 0.90 \\
\hline $\begin{array}{l}\text { Educational } \\
\text { level }\end{array}$ & Bachelor degree & Illiterate & 1.32 & 0.03 & 1.02 & 1.68 \\
\hline Marital status & Single & Married & 0.77 & 0.00 & 0.65 & 0.90 \\
\hline Marital status & Divorced & Married & 0.73 & 0.00 & 0.63 & 0.86 \\
\hline $\begin{array}{l}\text { Occupation } \\
\text { condition }\end{array}$ & Farmer & Others & 0.53 & 0.00 & 0.36 & 0.77 \\
\hline Referred from & Court & Psychiatrist & 0.74 & 0.02 & 0.46 & 0.57 \\
\hline Type of disorder & Mood & Psychosis & 1.51 & 0.00 & 1.32 & 1.71 \\
\hline Type of disorder & Mood and anxiety & Psychosis & 1.69 & 0.00 & 1.40 & 2.04 \\
\hline Type of disorder & $\begin{array}{l}\text { Substance } \\
\text { dependence }\end{array}$ & Psychosis & 1.82 & 0.00 & 1.53 & 2.16 \\
\hline Type of disorder & $\begin{array}{c}\text { Substance } \\
\text { dependence and } \\
\text { anxiety }\end{array}$ & Psychosis & 2.67 & 0.00 & 1.34 & 5.4 \\
\hline Type of disorder & Anxiety & Psychosis & 2.85 & 0.00 & 2.35 & 3.44 \\
\hline $\begin{array}{l}\text { Type of } \\
\text { treatment }\end{array}$ & $\begin{array}{l}\text { Psychotherapy, } \\
\text { Pharmacother- } \\
\text { apy and } \\
\text { ECT }\end{array}$ & Pharmacotherapy & 0.50 & 0.00 & 0.36 & 0.69 \\
\hline $\begin{array}{l}\text { Type of } \\
\text { treatment }\end{array}$ & $\begin{array}{l}\text { Psychotherapy, } \\
\text { Pharmacother- } \\
\text { apy, ECT and } \\
\text { OT }\end{array}$ & Pharmacotherapy & 0.29 & 0.00 & 0.13 & 0.63 \\
\hline $\begin{array}{l}\text { Type of } \\
\text { treatment }\end{array}$ & $\begin{array}{l}\text { Pharmacotherapy } \\
\text { and ECT }\end{array}$ & Pharmacotherapy & 0.55 & 0.00 & 0.48 & 0.63 \\
\hline $\begin{array}{l}\text { Type of } \\
\text { treatment }\end{array}$ & $\begin{array}{l}\text { Pharmacotherapy, } \\
\text { ECT and OT }\end{array}$ & Pharmacotherapy & 0.40 & 0.00 & 0.28 & 0.56 \\
\hline $\begin{array}{l}\text { Type of } \\
\text { treatment }\end{array}$ & $\begin{array}{l}\text { Pharmacotherapy } \\
\text { and OT }\end{array}$ & Pharmacotherapy & 0.58 & 0.00 & 0.47 & 0.71 \\
\hline $\begin{array}{l}\text { Type of } \\
\text { treatment }\end{array}$ & $\begin{array}{l}\text { Psychotherapy } \\
\text { and Pharma- } \\
\text { cotherapy }\end{array}$ & Pharmacotherapy & 0.86 & 0.02 & 0.76 & 0.98 \\
\hline $\begin{array}{l}\text { Duration of } \\
\text { disorder(years) }\end{array}$ & . & . & 1.09 & 0.04 & 1.03 & 1.32 \\
\hline
\end{tabular}

the married cases) lacked the adequate family support and possibly had the poor compliance to the treatment. The patients with the higher educational level and the jobs other than farmers and illiterates had a longer hospitalization period, respectively. In a study conducted in Nigeria, it was observed that the married people were less stayed, and the variables including age, gender, and employment status have a little impact on patients' length of hospitalization (15).

In the present study, the type of disorder and type of treatment had a significant effect on the length of hos- pitalization. The mood disorder, substance dependence, and anxiety disorders had a longer hospitalization period compared with the patients with psychotic disorders. Furthermore, patients with both mood and anxiety disorders and/or substance dependence and anxiety disorders had a longer total inpatient days compared with the schizophrenia patients. However, the study conducted in Razi psychiatric hospital in 2000 indicated that the patients with schizophrenia have a longer length of stay in hospitals than the patients with mood and other disorders (16).

The patients with a longer length of hospitalization 
and duration of disorder, patients with somatic problems, and single and divorced patients had a longer hospitalization time than the married patients and the patients who had insurance facility (16).

In a study conducted on the elderly in South Korea, the male and schizophrenia patients had a longer stay in hospital (17); however, in this study, there was no significant difference in gender and the length of hospitalization.

In the patients with mood disorder, the children aged 0 - 14 years compared with the 30 - 40 years had a lower hospitalization time. In addition, the patients with a higher educational level had a longer hospitalization time than other patients. In the patients with mood disorder, the rural patients had a longer hospital stay than the urban patients since it is estimated that in the rural areas no appropriate facilities can be found. The results indicated that the people with personal demand for hospitalization spent less inpatient period compared with the patients referred by a psychiatrist. Type of treatment had a significant relationship with hospitalization period. The patients treated with psychotherapy, pharmacotherapy and occupational therapy (OT) or psychotherapy, pharmacotherapy, electroconvulsive therapy (ECT) and OT or pharmacotherapy and OT or pharmacotherapy and ECT or pharmacotherapy, and ECT and OT had a shorter hospital stay compared with the patients only under pharmacotherapy. Despite the clear need for psychiatric intervention for the patients, providing necessary treatment for patients is often not an easy task. Unfortunately, the same disorders that impair a person's mood, thoughts, and functioning also impair his or her insight and judgment, leading to the refusal of care which is common in psychiatry.

Patients with psychosis and those with suicide attempt had a longer hospital stay than other patients. These patients with a previous psychiatric hospitalization, hospitalization during the religious months, and agricultural seasons had a shorter inpatient period than others. Patients with bachelor degree and expatriate patients compared with the illiterate and native patients experienced more hospitalization period.

In substance dependent patients, patients with insurance facilities had a longer hospital stay. Furthermore, patients with more number of children had a longer hospital stay. These patients under pharmacotherapy and OT had a shorter hospital stay compared with the patients only under pharmacotherapy. Occupational therapists work as members of multidisciplinary teams in the assessment and treatment of people experiencing alcohol and drugrelated problems. They assist their clients in both detoxification and rehabilitation phases of treatment and provide the appropriate follow-up and support, as well. Occupational therapists contribute in both group and individual counseling skills and they also focus specifically on maximizing self-efficacy and competence to perform life skills. They provide activity-based programs which can enhance the existing skills and the acquisition of new skills, as well.

Patients suffering from mood disorders as well as anxiety disorders had a shorter hospital stay on the religious months. Those patients aged 45 to 60 years had a longer hospital stay than those aged 30 to 44 years.

Type of treatment had a significant relationship with the length of hospital stay. On the other hands, this study showed that there was a significant relationship between hospital stay period and factors such as substance dependence, psychotic diseases, and the history of homicide.

\subsection{Conclusions}

Although hospitalization is increasingly restricted, development of strategies to manage the risk of violence in the community has been prioritized. Such strategies are formal procedures to evaluate the risk of violent behavior, better monitoring of outpatient treatment, greater attention to comorbidity with substance abuse and the increasing efforts to improve the rates of compliance with treatment. On the other hands, based on results of this study a correct registration system of patients' characteristics is proposed.

\section{Acknowledgments}

Thanks to the deputy of research and technology to provide the finance and to the medical documentation staff of the Zare psychiatric hospital to provide the data, as well.

\section{Footnotes}

Authors' Contribution: Jamshid Yazdani-Charati and Mehran Zarghami conceived and designed the evaluation. Abolfazl Hossein Nattaj, Zahra Faghani, and Ameneh Sheikholeslami collected the clinical data. Mehran Zarghami interpreted the clinical data. Abolfazl Hossein Nattaj and Jamshid Yazdani-Charati performed the statistical analysis. Jamshid Yazdani-Charati, Zahra Faghani, Ameneh Sheikholeslami, and Mohammad Vahedi drafted the manuscript. Jamshid Yazdani-Charati and Mehran Zarghami revised it critically for important intellectual content. All authors read and approved the final manuscript.

Funding/Support: This study has been financially supported by a grant (547) from the research vice chancellor of the Mazandaran University of Medical Sciences.

Declaration of Interest: The authors declare that they have no competing interests. 


\section{References}

1. Charles P. Health Economics. Tehran: Eghtesad Nou Publication;1997.

2. Ersoy K, Kavuncubasi S, Ozcan YA, Harris J2. Technical efficiencies of Turkish hospitals: DEA approach. J Med Syst. 1997;21(2):67-74. [PubMed: 9297615].

3. Mills A. The economics of hospitals in developing countries. Part I: expenditure patterns. Health Policy Plan. 1990;5(2):107-17. doi: 10.1093/heapol/5.2.107.

4. Heartfield M. Regulating hospital use: length of stay, beds and whiteboards. Nurs Inq. 2005;12(1):21-6. doi:10.1111/j.1440-1800.2005.00251.x. [PubMed: 15743439].

5. Atienza N, Garcia-Heras J, Munoz-Pichardo JM, Villa R. An application of mixture distributions in modelization of length of hospital stay. Stat Med. 2008;27(9):1403-20. doi: 10.1002/sim.3029. [PubMed: 17680551].

6. Borghans I, Heijink R, Kool T, Lagoe RJ, Westert GP. Benchmarking and reducing length of stay in Dutch hospitals. BMC Health Serv Res. 2008;8:220. doi: 10.1186/1472-6963-8-220. [PubMed: 18950476].

7. Barnum H, Kutzin J. Public hospitals in developing countries: resource use, cost, financing. Johns Hopkins University Press; 1993.

8. Department of Economic and Social Affairs . World population aging 2009. New York: United Nations; 2010.

9. Naghavi M, Abolhassani F, Pourmalek F, Jafari N, Moradi Lakeh M, Eshrati B, et al. The burden of disease and injury in Iran in the year 2003. Iran J Epidemiol. 2008;4(1):1-19.
10. Kheyri S, Faghiehzadeh S, Meshkani MR, Mahmoudi M, Babaei GH. A comparison of cox and frailty models in presence of unknown risk factors. J Res Med Sci. 2003;8(2)

11. Yazdani-Charati J, Zarghami M, Saadat S. Determining the factors affecting recurrence in bipolar I disorder using Andersen-Gill counting process model. J Mazandaran Univ Med Sci (JMUMS). 2014;23(108).

12. Ghorbani Gholiabad S, Yazdani Cherati J, Jan Babai G, Shabankhani B. Survival of Patients with Gastric Cancer in Mazandaran Province, 2007-2012. J Mazandaran Univ Med Sci (JMUMS). 2013;23(100).

13. Kieinbaum D. Survival Analysis, A Self, Learning text. New York: Springer; 1996.

14. Montaseri M, Yazdani Charati J, Espahbodi F, Mousavi SJ. Five-year Survival Rate in Hemodialysis Patients Attending Sari Imam Khomeini Hospital. J Mazandaran Univ Med Sci. 2013;23(101):78-85.

15. Adegunloye OA, Yussuf AD, Ajiboye PO, Issa BA, Buhari OIN. Correlates of length of stay among psychiatric in-patients in a tertiary health institution in Nigeria. Res J Med Sci. 2009;3:56-61.

16. Fakharian F, Mazianani R, Fadaei F. Study of the Effective Factors on Lenght of Stay among Psychiatric Patients in Razi Hospital. J Rehabil. 2002;3(3):33-7.

17. Chung W, Oh SM, Suh T, Lee YM, Oh BH, Yoon CW. Determinants of length of stay for psychiatric inpatients: analysis of a national database covering the entire Korean elderly population. Health Policy. 2010;94(2):120-8. doi: 10.1016/j.healthpol.2009.09.004. [PubMed 19783062]. 